\title{
A Computer Assistant for Remote Collaborative Troubleshooting of Domestic Medical Instruments
}

\author{
Olivier A. Blanson Henkemans, Vanessa M. \\ Sawirjo, Charles A.P.G. van der Mast \\ Human Machine Interaction group \\ Delft University of Technology \\ Delft, the Netherlands \\ O.A.BlansonHenkemans@TUDelft.nl
}

\author{
Mark A. Neerincx, Jasper Lindenberg \\ TNO Defense, Security \& Safety \\ Soesterberg, the Netherlands \\ Mark.Neerincx@TNO.nl
}

\begin{abstract}
Patients suffering from chronic illness, such as diabetes, use various domestic instruments as part of their selfcare. For older adults, there is a need for assistance to use the instruments adequately and to solve technical failures. Following the eHealth concept, we designed a computer assistant for an older adult and a technical specialist, which supports remote collaborative troubleshooting which tailors the feedback to the users' needs. We evaluated two feedback styles, i.e., cooperative and directive, in the TNO Experience lab, with older and younger adults playing the role of patient and technical specialist, respectively, in "failure scenarios". Results show that most effective troubleshooting occurs with teams consisting of a older patient receiving cooperative feedback and a younger technical specialist receiving directive feedback. In addition, the patient experienced more effort than the technical specialist. Further, different personal characteristics had moderating effects on the evaluation of the feedback styles. Our study concluded that different user groups require different feedback styles and that computer assistance for remote collaborative troubleshooting will be optimal when this feedback is personalized.
\end{abstract}

Keywords: eHealth, medical instruments, troubleshooting, CSCW, computer assistant, personalized feedback.

\section{INTRODUCTION}

John (58) has diabetes type II and as part of his self-care he monitors his health with the use of domestic medical instruments, such as a glucometer. For John, it is essential that these instruments work accurately as his other self-care activities, e.g., diet, exercise and medication regime, depend on it. In case of a technical failure, John experiences difficulty resolving the failure due to low frequency of occurrence, complex operating manuals, and the need for accurate operation. He generally prefers to call the help desk that remotely supports him with the troubleshooting process. However, John, frequently, as an older novice user, faces challenges when communicating on the phone with a younger technical specialist.

Like John, many patients face similar challenges. They are dependent on domestic medical instruments to make educated choices in their self-care [1], but experience problems troubleshooting technical failures. Although medical instruments are described as easy to use, previous research finds them to be anything but [2].

Research was supported by SenterNovem IOP-MMI, of the Dutch Ministry of Economic Affairs, supporting the SuperAssist project.
Patients and the health care service can potentially benefit from eHealth. Remote care for people at home through information and communication technology (ICT) has multiple benefits, such as lowering costs, aging in place, and monitoring and assessing care needs [3]. A previous study showed that a computer assistant can improve the troubleshooting of medical instruments by a patient at home [4]. Following the eHealth concept, we added functions to the assistant that support remote collaborative troubleshooting of domestic medical instruments (Fig. 1). The patient and technical specialist each have a personal computer assistant that detects failures and provides assistance through feedback and demonstration. In addition, they mediate the communication between the patient and technical specialist, by offering relevant information of user, usage and context.

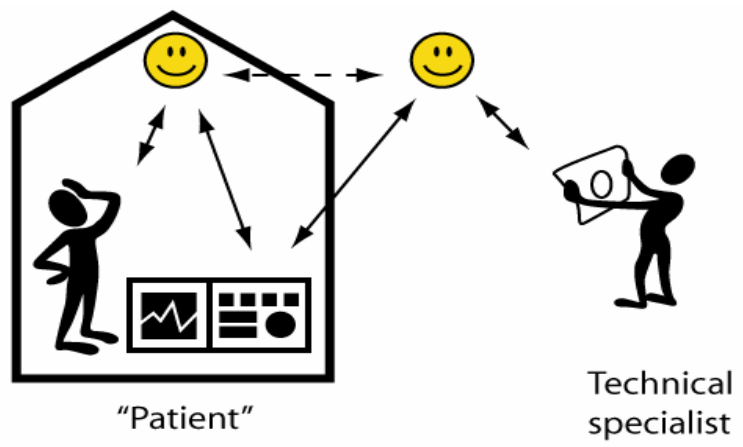

Figure 1. Patient and technical specialist have a personal computer assistant that monitors the environment, supports troubleshooting and mediates communication through verbal, textual and graphical demonstration.

To facilitate support of the patient and technical specialist, the computer assistant has two requirements. First, it should support troubleshooting, defined as a search for likely causes of faults through a potentially erroneous problem space of possible causes [5]. Second, it should support remote collaboration [6] between older novice patients in their home environment and younger technical specialists in their professional environment. The latter implies it should provide relevant information and accommodate feedback to different users with different types of personal characteristics, such as age, expertise and cognitive abilities [7].

In a previous study [4] we evaluated the influence of different computer assistant feedback styles on supervision of 
individuals in complex task environments. The assistant provided cooperative feedback, i.e., it has a coaching character, explains and educates, and expects high participation of the users, or directive feedback, i.e., it has an instructing character with brief reporting and expects low participation of the user. Results showed that the cooperative assistant was more effective and satisfactory, whereas the directive assistant was more efficient. Furthermore, personal characteristics, i.e., cognitive abilities and personality traits, proved to have a moderating effect on how people evaluated the assistant.

Consequently, our main research question reads, is a computer assistant applying different feedback styles suitable for remote collaborative troubleshooting? From our earlier findings, we formed two assumptions. First, a cooperative feedback style is oriented towards user satisfaction and longterm development and the directive dialogue mode is oriented towards quick and efficient problem solving in cases of anomalies. Thus, we expect the best team performance for a patient receiving cooperative and a technical specialist receiving directive feedback. Second, personal characteristics will moderate how the users evaluated the assistant.

In medical research on human subjects, consideration of their wellbeing should take precedent over the interest of science. Although we are empirically studying the use of a computer assistant and its benefit to the end user, we do not want to inordinately hinder them [8]. In collaboration with Leiden University Medical Center, we conducted domain, task and scenario analyses with diabetes patients and interviewed diabetic specialists. In the current study, we evaluated an intelligent assistant with subjects who are not diabetics, but resemble the prospective users. Following, a computer assistant prototype we developed and evaluated the patients in a field study. To validate our hypotheses, we conducted a laboratory experiment at the TNO Experience Lab, with older adults, playing the role of patient, and younger adults, playing the role of technical specialist, performing activities according to scenarios. A benefit of this Smart Home Environment is the opportunity to facilitate natural behavior in a controlled environment [9].

\section{DESIGN OF COMPUTER ASSISTANT}

The computer assistants interact with the patient and the technical specialist through a Patient and Technical Specialist Interface, respectively. Both interfaces consist of an assistant feedback window and chat service, which facilitates communication between the older adult and technical specialist. In addition, the Patient Interface displays the interface of the medical instrument currently in use.

The patient's assistant monitors the medical instruments, i.e., glucometer, blood pressure meter and digital pill box. In case of a malfunction, it notifies the technical specialist's assistant. The assistants mediate the communication between patient and technical specialist. The mediation follows the general conceptualization of troubleshooting [10], which consists of representing the problem (assessing discrepancies between the system's current state and ideal state); diagnosis or fault isolation, including exploring the problem space, generating hypotheses, gathering information, hypothesis evaluation and decision making; selecting, implementing and evaluating solution options; adding experience to knowledge database. To generate feedback, the assistant's knowledge and reasoning is based on the medical instruments' operation manual. The manual serves as reference for the assistant, concerning the possible errors, cause, and solution. Table I depicts the different actors and their troubleshooting activities.

TABLE I. ACTIVITIES OF OLDER PATIENT, YOUNGER TECHNICAL SPECIALIST AND COMPUTER ASSISTANTS DURING TROUBLESHOOTING PROCESS

\begin{tabular}{|c|c|c|c|}
\hline Patient(P) & $\begin{array}{c}\text { P Computer } \\
\text { Assistant(PCA) }\end{array}$ & $\begin{array}{c}\text { TS Computer } \\
\text { Assistant(TSCA) }\end{array}$ & $\begin{array}{c}\text { Technical } \\
\text { Specialist(TS) }\end{array}$ \\
\hline \multicolumn{4}{|c|}{ Define problem field } \\
\hline $\begin{array}{l}\text { Observe } \\
\text { current } \\
\text { instrument } \\
\text { state; } \\
\text { Establish } \\
\text { problem }\end{array}$ & $\begin{array}{l}\text { Monitor medical } \\
\text { instrument } \\
\text { technical data; } \\
\text { Establish problem; } \\
\text { Send overview to } \\
\text { P \& TSCA }\end{array}$ & $\begin{array}{l}\text { Receive overview } \\
\text { problem from } \\
\text { TSCA; } \\
\text { Present problem to } \\
\text { TS }\end{array}$ & $\begin{array}{l}\text { Receive } \\
\text { overview } \\
\text { problem }\end{array}$ \\
\hline \multicolumn{4}{|c|}{ Diagnosis } \\
\hline $\begin{array}{l}\text { Receive } \\
\text { diagnosis } \\
\text { from PCA }\end{array}$ & $\begin{array}{l}\text { Receive diagnosis } \\
\text { from TSCA; } \\
\text { Present diagnosis } \\
\text { to } \mathrm{P}\end{array}$ & $\begin{array}{l}\text { Provide relevant } \\
\text { data from } \\
\text { knowledge } \\
\text { database to TS; } \\
\text { Receive diagnosis } \\
\text { from TS; } \\
\text { Send diagnosis to } \\
\text { PCA }\end{array}$ & $\begin{array}{l}\text { Start diagnosis } \\
\text { process; } \\
\text { Receive } \\
\text { relevant data } \\
\text { from } \\
\text { knowledge } \\
\text { database from } \\
\text { TSCA; } \\
\text { Send diagnosis } \\
\text { to TSCA }\end{array}$ \\
\hline \multicolumn{4}{|c|}{ Perform compensatory actions } \\
\hline $\begin{array}{l}\text { Receive } \\
\text { compensatory } \\
\text { actions from } \\
\text { PCA; } \\
\text { Manipulate } \\
\text { instrument }\end{array}$ & $\begin{array}{l}\text { Receive } \\
\text { compensatory } \\
\text { actions from } \\
\text { TSCA; } \\
\text { Present } \\
\text { compensatory } \\
\text { actions to P } \\
\text { Check success of } \\
\text { compensatory } \\
\text { action }\end{array}$ & $\begin{array}{l}\text { Provide relevant } \\
\text { data from } \\
\text { knowledge } \\
\text { database to TS; } \\
\text { Receive } \\
\text { compensatory } \\
\text { actions from TS; } \\
\text { Send } \\
\text { compensatory } \\
\text { actions to PCA }\end{array}$ & $\begin{array}{l}\text { Start repair } \\
\text { process; } \\
\text { Receive } \\
\text { relevant data } \\
\text { from TSCA; } \\
\text { Establish } \\
\text { compensatory } \\
\text { actions; } \\
\text { Send } \\
\text { compensatory } \\
\text { actions to } \\
\text { TSCA }\end{array}$ \\
\hline \multicolumn{4}{|c|}{ Store comments to knowledge database } \\
\hline $\begin{array}{l}\text { Add } \\
\text { comments to } \\
\text { knowledge } \\
\text { database } \\
\end{array}$ & $\begin{array}{l}\text { Add process } \\
\text { knowledge } \\
\text { database }\end{array}$ & $\begin{array}{l}\text { Add process } \\
\text { knowledge } \\
\text { database }\end{array}$ & $\begin{array}{l}\text { Add comments } \\
\text { to knowledge } \\
\text { database }\end{array}$ \\
\hline
\end{tabular}

To illustrate the function of the computer assistant, Fig. 2 shows the interface of patient John experiencing technical problems with his glucometer and Fig. 3 shows the interface of the supporting specialist. The assistant provides relevant information about the problem field and mediates the communication between the patient and the technical specialist by suggesting relevant template sentences. The patient and the technical specialist collaboratively solve the failure. Finally, the process will be stored in the knowledge diary. The cooperative assistant supports the user by involving the user in the diagnosis process, explaining step by step the failure and cause, suggesting compensatory actions, and indicating how these problems can be prevented. In contrast, the directive assistant supports the user by stating the independently assessed failure and cause and instructing the compensatory actions. 


\section{EVALUATION}

Our goal was to evaluate the influence of cooperative and directive feedback styles on remote collaborative troubleshooting between teams consisting of an older patient and a younger technical specialist. Each team performed a scenario where patient and technical specialist both received cooperative feedback; a scenario where they both received directive feedback; a scenario where the patient received cooperative and the technical specialist received directive feedback; a scenario where the patient received directive and the technical specialist received cooperative feedback. To control for transfer effects, we counter-balanced the feedback combinations across the four scenarios.

Subjects were a sample of 16 younger and 16 older adults. The younger adults were aged between 19 and $35(\mathrm{M}=22$, $\mathrm{SD}=2.68$ ) and the older adults were aged between 42 and 80 $(M=59, S D=10.56)$. Eight younger adults were male and eight female. Ten older adults were male and six female. Subjects received a small incentive for their participation in this study which lasted 3 hours.

First, we surveyed subjects' demographics and computer experience and tested them on spatial ability. Also, we measured participants' locus of control (LOC). The locus of control theory [11] refers to two types of people: those with a predominantly internal locus of control (i.e., attribute events to their own control), and those with an external locus of control (i.e., attribute events to external circumstances).

Subjects collaboratively troubleshot medical instrument failures remotely through their interfaces according to four scenarios. The scenarios represent every day use of the medical instruments and possible failures that can occur. The older adults had to work with medical instruments. Examples of malfunctions are low battery, a stuck lever, and an erroneously placed pill. Subjects did not have prior knowledge about these medical instruments, but the technical specialists were instructed to study the operation manuals for a fixed time at the beginning of the experiment.

During the experiment, we observed the influence of the assistants' feedback styles on the experienced usability, concerning effectiveness, efficiency, and satisfaction. Effectiveness was measured by the number of technical failures that were solved. Efficiency was measured by logging the time required to solve a failure and mental effort experienced. Mental effort concerns the resources required to perform the task and was measured using the RSME [12]. After every scenario, subjects indicated on a scale ranging from 0 (no effort) to 150 (extreme effort), how much effort they experienced. Afterwards, to evaluate the satisfaction, we asked subjects which feedback style they preferred.

To evaluate the computer assistant feedback usability, we calculated the z-score (to compare performances on different tasks) and conducted a repeated measure ANOVA. The team members score similarly on objective variables effectiveness and time and we compared the different combination of feedback styles for each team. Team members scored differently on subjective variable effort and we compared the effort of the different individuals. To assess if participants had a preference for feedback style, we performed a $\chi^{2}$-test. To determine whether there was a relationship between personal characteristics and evaluation of the assistant's usability, we conducted multiple regression analyses on the participants' performance data with 6 predictors, i.e., age, gender, education level, computer experience, spatial ability (SPAT), and locus of control (LOC).

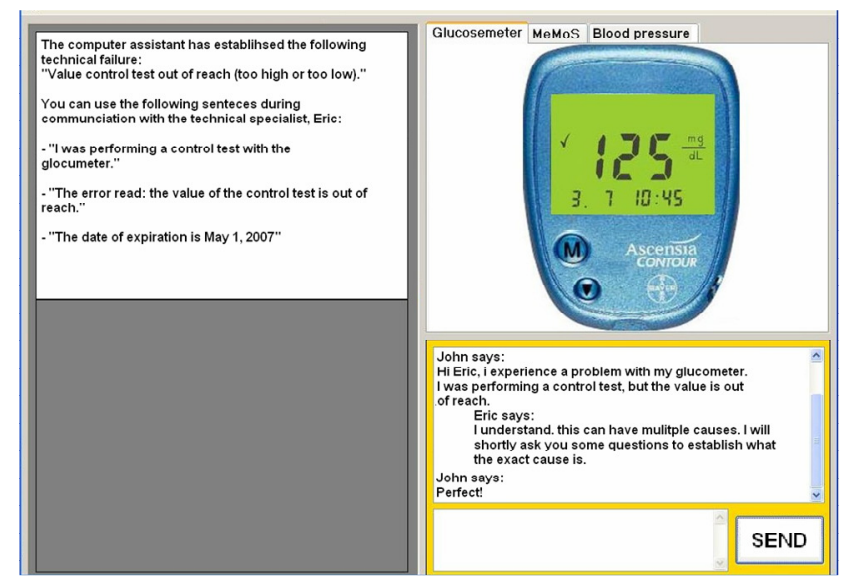

Figure 2. Patient Interface with computer assistant feedback frame, medical isntrument interface and chat service.

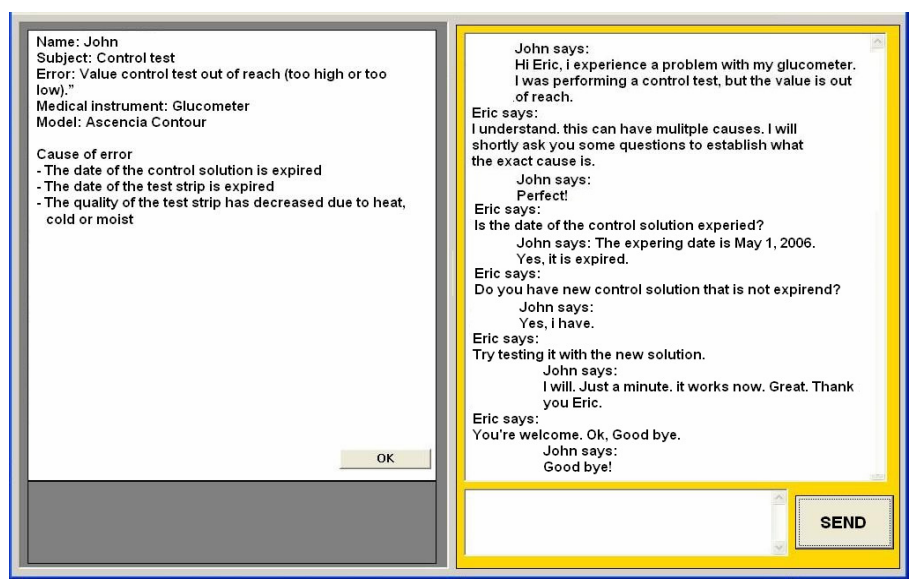

Figure 3. Technical Specialist Interface with computer assistant feedback frame and chat service.

\section{RESULTS}

Results show that feedback influences effectiveness. Fig. 4 shows the means and standard error of the different feedback combinations. Teams consisting of a patient receiving cooperative and technical specialist receiving directive feedback solved significantly more technical failures than the teams consisting of a patient receiving directive and a technical specialist receiving cooperative feedback, $\mathrm{F}(1,15)=2.09, \mathrm{p}<.05$.

Concerning efficiency, we studied time required and effort experienced while solving technical malfunctions. We did not find significant influence of different feedback combination on the time teams required. We did find that patients significantly experienced more effort $(M=.45, S D=.24)$ than technical specialists $(M=-.42, S D=.22), \mathrm{F}(1,15)=14.76, \mathrm{p}<.05$. 
To evaluate the subject's satisfaction with the feedback styles, we surveyed their preference. Of the older adults, 11 of the 16 subjects $(69 \%)$ indicated they preferred the cooperative feedback style, $\chi^{2}(1)=4.50, \quad \mathrm{p}<.05$. The younger adults' preference was bisect.

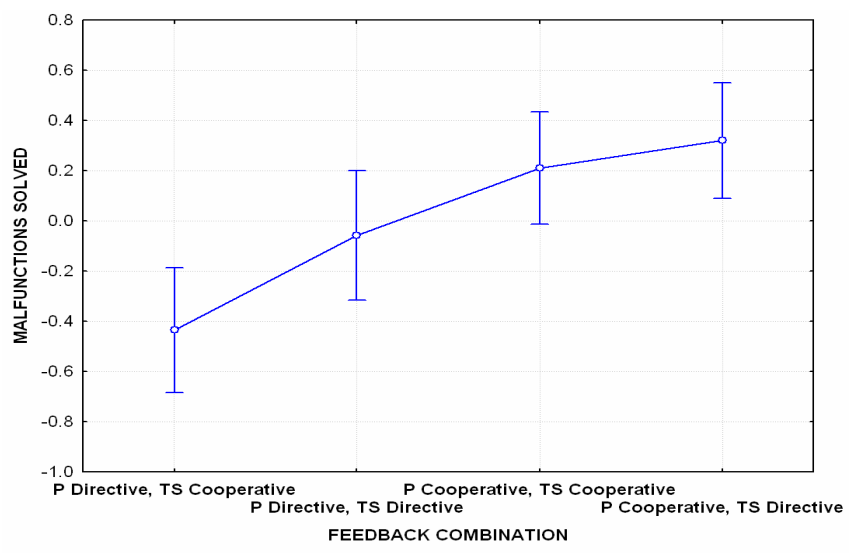

Figure 4. Effectiveness measured as malfunctions solved by teams consisting of patient $(\mathrm{P})$ and technical specialist (TS ) receiving different feedback i.e., cooperative and directive, combinations.

Results show that personal characteristics moderated the evaluation of the computer assistant. Table II and III list the factors that accounted for the variance in the evaluation by the patient and technical specialist, respectively, of the assistant's usability, concerning effectiveness, time, effort and preference.

TABLE II. PRECENTAGE OF VARIANCE IN PATIENTS' EVALUATION OF COMPUTER ASSISTANT'S USABILITY

\begin{tabular}{|c|l|c|l|}
\hline & \multicolumn{1}{|c|}{$\mathbf{F}$} & $\mathbf{R}^{2}$ & \multicolumn{1}{|c|}{ Factors (\%) } \\
\hline $\begin{array}{c}\text { Effective- } \\
\text { ness }\end{array}$ & $\mathrm{F}(5,10)=4.24, \mathrm{p}<.05$ & $68 \%$ & $\begin{array}{l}\text { Gender (33), Age (8), } \\
\text { Computer experience (12), } \\
\text { LOC (10), SPAT (5) }\end{array}$ \\
\hline Time & $\mathrm{F}(3,12)=6.93, \mathrm{p}<.05$ & $66 \%$ & $\begin{array}{l}\text { Age (54), Education (6), } \\
\text { SPAT (6) }\end{array}$ \\
\hline Preference & $\mathrm{F}(4,11)=4.46, \mathrm{p}<.05$ & $62 \%$ & $\begin{array}{l}\text { Spatial abilty (34), Age (11), } \\
\text { Education (15), LOC (4) }\end{array}$ \\
\hline
\end{tabular}

TABLE III. PERCENTAGE OF VARIANCE IN TECHNICAL SPECIALIST'S EVALUATION OF COMPUTER ASSISTANT'S USABILITY

\begin{tabular}{|c|l|c|l|}
\hline & \multicolumn{1}{|c|}{$\mathbf{F}$} & $\mathbf{R}^{\mathbf{2}}$ & \multicolumn{1}{c|}{ Factors (\%) } \\
\hline Effort & $\mathrm{F}(1,14)=3.63, \mathrm{p}<.05$ & $21 \%$ & Education $(21)$ \\
\hline Preference & $\mathrm{F}(1,14)=4.34, \mathrm{p}<.05$ & $24 \%$ & LOC $(24)$ \\
\hline
\end{tabular}

\section{DISCUSSION}

In this study, we evaluated a computer assistant that supports remote troubleshooting of domestic medical instruments. The patient and technical specialist each have an assistant that monitors their environment and provides feedback, either cooperative or directive, according to the general conceptualized troubleshooting process. Additionally, it mediates the communication by offering relevant contextual information.

In summary, teams consisting of a patient receiving cooperative feedback and a technical specialist receiving directive feedback were the most effective. Patients experienced more effort than technical specialist. Concerning satisfaction, older patients preferred the cooperative feedback style. In addition, other personal characteristics, i.e., gender, educational level, spatial ability, locus of control, and computer experience, influenced the evaluation of the feedback styles. These results correspond with earlier findings [4] showing that the cooperative style was more effective and satisfactory and personal characteristics have a moderating effect on evaluating telecare technology.

These results have an implication for the design of computer assistance for the support of remote collaborative troubleshooting. Users with different personal characteristics and level of technical expertise require different feedback styles. Also, older patients experience more effort then the younger specialists. A future design-requirement is to alleviate this difference. Only when the feedback style is well geared to different users, will the troubleshooting progress optimally.

In conclusion, the study displayed that the computer assistant was usable for remote collaborative troubleshooting technical failures that occur with domestic medical instruments. The assistants accommodate different users by providing different feedback styles. Consequently, the assistants have the potential to help different users, such as older patients and younger technical specialists collaborate successfully.

\section{REFERENCES}

[1] A. L. Mykityshyn, A. D. Fisk, and W. A. Rogers. "Learning to use a home medical device: mediating age-related differences with training," Human Factors, 2002, vol. 44(3), pp. 354-64.

[2] W. A. Rogers, A.L. Mykityshyn, R. H. Campbell, and A. D. Fisk, "Only 3 easy steps? User-centered analysis of a "simple" medical device," Ergonomics in Design, 2001, vol. 9, pp. 6-14.

[3] Business Insights, "ICT Opportunities in Healthcare: Key issues, growth prospects and market opportunities in Europe and the US," RBI142; 2005.

[4] O. A. Blanson Henkemans, M. A. Neerincx, J. Lindenberg, C. A. P. G. van der Mast, "SuperAssist: A User-Assistant Collaborative Environment for the supervision of medical instrument use at home." $1 \mathrm{st}$ International Conference on Pervasive Computing Technologies for Healthcare, 2006, Nov 29-Dec 1, Innsbruck, Austria.

[5] A. Schaafstal, J. M. Schraagen, and M. van Berlo, "Cognitive task analysis and innovation of training: The case of structured troubleshooting," Human Factors, 2000, vol. 42, no. 1, pp. 75-86.

[6] P. Dourish, "Re-Space-ing Place: "Place" and "Space" Ten Years On." CSCW'06, 2006, November 4-8, Banff, Alberta, Canada.

[7] S. J. Czaja, N. Charness, A. D. Fisk, C. Hertzog, S.N. Nair, W.A. Rogers, and J. Sharit, "Factors Predicting the Use of Technology: Findings From the Center for Research and Education on Aging and Technology Enhancement (CREATE)". Psychology and Aging, 2006, vol. 21(2), pp. 333-352.

[8] C. Coyle, G. Doherty, M. Matthews, and J. Sharry, "Computer in talkbased mental health interventions," Interacting with Computers, 2007, vol. 19 , pp. 545-562.

[9] O. A. Blanson Henkemans, K. E. Caine, W. A. Rogers, A. D. Fisk, M. A. Neerincx, B. de Ruyter, «Medical Monitoring for Independent Living: User-Centered Smart Home Technologies for Older Adults," M. Jordanova and F. Lievens, Eds. Proceedings of Med-e-Tel 2007, Apr 1820, Luxemburg, Luxemburg;.

[10] D. H. Jonassen, J. Howland, J. Moore, and R. M. Marra, "Learning to solve problems with technology: A constructivist perspective," 2nd. Ed. Columbus, OH: Merrill/Prentice-Hall, 2003.

[11] J. Rotter, "Generalized expectancies for internal versus external control of reinforcements," Psychological Monographs, 1966, vol. 80, pp. 1-28.

[12] F. R. H. Zijlstra, Efficiency in work behaviour: A design approach for modern tools, Delft: Delft University Press, 1993. 